\title{
Pain in Intellectually Disabled Children: Towards Evidence-Based Pharmacotherapy?
}

\author{
Abraham J. Valkenburg ${ }^{1,3}$ Tom G. de Leeuw ${ }^{3,4}$ - Monique van Dijk ${ }^{1,2,3}$ • \\ Dick Tibboel $^{1,3}$
}

Published online: 16 June 2015

(C) The Author(s) 2015. This article is published with open access at Springerlink.com

\begin{abstract}
This critical opinion article deals with the challenges of finding the most effective pharmacotherapeutic options for the management of pain in intellectually disabled children and provides recommendations for clinical practice and research. Intellectual disability can be caused by a wide variety of underlying diseases and may be associated with congenital anomalies such as cardiac defects, small-bowel obstructions or limb abnormalities as well as with comorbidities such as scoliosis, gastro-esophageal reflux disease, spasticity, and epilepsy. These conditions themselves or any necessary surgical interventions are sources of pain. Epilepsy often requires chronic pharmacological treatment with antiepileptic drugs. These
\end{abstract}

Abraham J. Valkenburg

a.valkenburg@erasmusmc.nl

1 Intensive Care and Department of Pediatric Surgery, Erasmus University Medical Center-Sophia Children's Hospital, Dr. Molewaterplein 60, 3015 GJ Rotterdam, The Netherlands

2 Division of Neonatology, Department of Pediatrics, Erasmus University Medical Center-Sophia Children's Hospital, Rotterdam, The Netherlands

3 Pain Expertise Center, Erasmus University Medical Center, Rotterdam, The Netherlands

4 Department of Anesthesiology, Erasmus University Medical Center-Sophia Children's Hospital, Rotterdam, The Netherlands antiepileptic drugs can potentially cause drug-drug interactions with analgesic drugs. It is unfortunate that children with intellectual disabilities often cannot communicate pain to caregivers. Although these children are at high risk of experiencing pain, researchers nevertheless often have to exclude them from trials on pain management because of ethical considerations. We therefore make a plea for prescribers, researchers, patient organizations, pharmaceutical companies, and policy makers to study evidence-based, safe and effective pharmacotherapy in these children through properly designed studies. In the meantime, parents and clinicians must resort to validated pain assessment tools such as the revised FLACC scale.

\section{Key Points}

The management of pain in intellectually disabled children is challenging in view of the limited possibilities for pain assessment, the high incidence of comorbidities, and the use of co-medication.

Adequate pain assessment is the cornerstone of pain management, and pain in intellectually disabled children must be assessed with validated pain assessment tools only.

Prescribers must be aware of the potential alterations in pharmacokinetics and pharmacodynamics of analgesics in intellectually disabled children, such as drug-drug interactions with antiepileptic drugs.

Analysis of the pharmacokinetics of analgesics is justified if large differences in effect or safety between children with and without intellectual disabilities can be expected. 


\section{Introduction}

The American Association on Intellectual and Developmental Disabilities (AAIDD) defines intellectual disability as "A disability characterized by significant limitations both in intellectual functioning and in adaptive behavior, which covers many everyday social and practical skills. This disability originates before the age of 18" [1]. Intellectual disability is associated with a wide variety of underlying disorders, which are categorized into chromosomal abnormalities, single gene disorders, mitochondrial disorders, and environmental disorders. Table 1 lists the disorders in each of these categories; it is clear that the group of intellectually disabled children is quite heterogeneous. The prevalence of severe intellectual disability $(\mathrm{IQ}<50)$ across Europe varies from 3.0 to 5.1 per 1000 inhabitants [2]. Incidences of the various underlying disorders vary widely, and Down syndrome is the most common congenital anomaly underlying intellectual disability; in the Netherlands the incidence of Down syndrome is reported to be 14.57 per 10,000 births [3]. However, the cause of the intellectual disability cannot always be identified [4]. Depending on the cause of the

Table 1 Underlying causes of intellectual disability

\begin{tabular}{|c|c|}
\hline Category & Examples of syndromes/disorders \\
\hline $\begin{array}{l}\text { Chromosomal } \\
\text { abnormalities }\end{array}$ & $\begin{array}{l}\text { Down syndrome } \\
\text { Angelman syndrome } \\
\text { Prader-Willi syndrome } \\
\text { DiGeorge syndrome }\end{array}$ \\
\hline \multicolumn{2}{|l|}{ Single gene disorders } \\
\hline $\mathrm{X}$-linked disorders & $\begin{array}{l}\text { Fragile X syndrome } \\
\text { MECP2-related disorders (including Rett } \\
\text { syndrome) }\end{array}$ \\
\hline $\begin{array}{l}\text { Autosomal } \\
\text { dominant disorders }\end{array}$ & $\begin{array}{l}\text { De novo mutations (i.e., STXPB1, SYGAP1, } \\
\text { SCN2A) }\end{array}$ \\
\hline $\begin{array}{l}\text { Autosomal } \\
\text { recessive disorders }\end{array}$ & PRSS12, CRBN, GRIK2 \\
\hline \multirow{2}{*}{$\begin{array}{l}\text { Mitochondrial } \\
\text { disorders }\end{array}$} & Leigh syndrome \\
\hline & $\begin{array}{l}\text { MELAS (Mitochondrial encephalomyopathy } \\
\text { with lactate acidosis and stroke-like } \\
\text { episodes) }\end{array}$ \\
\hline \multicolumn{2}{|c|}{ Environmental disorders } \\
\hline Prenatal causes & $\begin{array}{l}\text { Congenital infections } \\
\text { Environmental toxins or teratogens }\end{array}$ \\
\hline Perinatal causes & $\begin{array}{l}\text { Preterm birth, hypoxia, infection, trauma, } \\
\text { intracranial hemorrhage }\end{array}$ \\
\hline Postnatal causes & $\begin{array}{l}\text { Trauma, central nervous system hemorrhage, } \\
\text { hypoxia, toxins }\end{array}$ \\
\hline
\end{tabular}

Derived from Pivalizza P, Lalani SR. UpToDate: intellectual disability (mental retardation) in children: evaluation for a cause. Last accessed: January 152015 intellectual disability, various areas of the brain involved in the motivational-affective, cognitive-evaluative aspects of pain, as well as autonomic responses to pain, can be affected [5]. However, for children with birth asphyxia, it is still unclear what the effect of the injury is on the different aspects of the pain experience.

Many intellectually disabled children receive antiepileptic drugs. Older antiepileptic drugs are known for their enzyme inducing and inhibiting effects [6], and the consequences of these effects on treatment with analgesic drugs will be discussed below.

When John Langdon Down wrote his 1887 treatise on what we now refer to as individuals with Trisomy 21 , he stated that "Common sensation is generally much less acute than in ordinary persons. Pain is born with wonderful callousness. It is not uncommon for children of this class to allow a thecal abscess to be opened with a scalpel without a grimace or without uttering a word" [7].

This passage perfectly describes the challenges caregivers face when managing pain in intellectually disabled children. Children with intellectual disabilities are often unable to communicate pain to caregivers. Researchers will therefore often exclude these children from trials on pain management, and all the more so as inclusion would involve special ethical considerations [8,9]. That intellectually disabled children often are excluded from research is supported by the findings of Belew et al. that no more than $0.03 \%$ of the publications on pain in humans addressed pain in intellectually disabled children [10].

The altered pain responses of children with intellectual disabilities have been noted and, as a result, various observational pain assessment tools have been developed for this group. These tools will be discussed as in subsequent sections.

This critical opinion article deals with the challenges of finding the most effective pharmacotherapeutic options for the management of pain in intellectually disabled children and provides recommendations for clinical practice and research.

\section{Pain Response}

Pain responses in preverbal and nonverbal children may vary on the basis of developmental differences, pain experiences, and perhaps unknown genetic and hereditary traits. In children with intellectual disabilities, the interpretation of pain responses is even more complicated because of the heterogeneity of underlying conditions, children's level of developmental delay, or the presence of painful comorbidities. As these children often show idiosyncratic behavior in response to pain, there is 


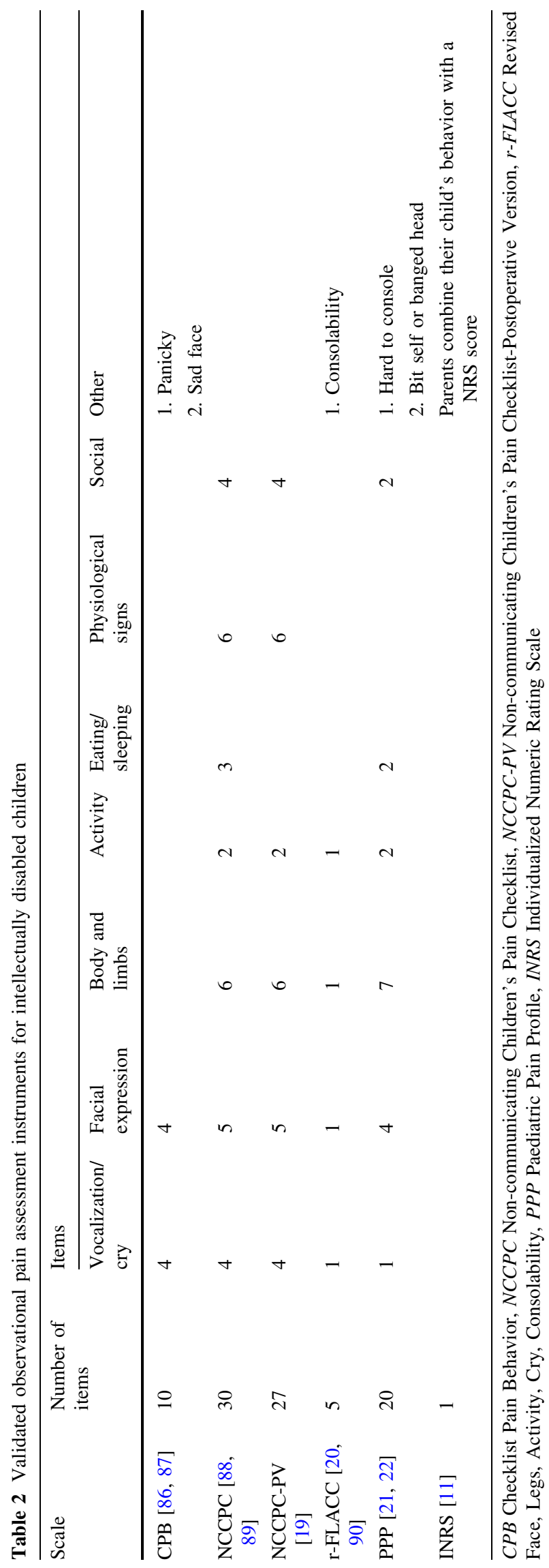

consensus among healthcare providers that parents are the best informants of their child's pain expression because they know how their child expresses discomfort or comfort in daily life [11]. That is valuable information when dealing with the assessment of, for example, postoperative pain in those children. With respect to chronic or persistent pain, it is even more difficult to identify pain-related behavior.

\section{Adequate Pain Assessment}

The International Association for the Study of Pain (IASP) formulated the following definition of pain in 1979: "Pain is an unpleasant sensory and emotional experience associated with actual or potential tissue damage, or described in terms of such damage" [12]. This definition still stands today. Anand and Craig addressed in 1996 the limitations of this definition, arguing that it is not applicable to individuals incapable of self-report such as infants, young children, and intellectually disabled individuals [13]. In the note that comes with the definition, IASP therefore later added: "The inability to communicate verbally does not negate the possibility that an individual is experiencing pain and is in need of appropriate pain-relieving treatment".

The ability to accurately measure pain is one of the pillars in successful clinical pain management [14]. Selfreport is regarded as the gold standard for the measurement of pain in children from the age of 4 years and in adults [15]. Observational pain assessment, usually performed by nurses, is considered the silver standard in children younger than 4 years, sedated or mechanically ventilated children, and intellectually disabled children.

Table 2 gives the available pain assessment instruments validated for children with intellectual disabilities. They vary from relatively simple and easy to use (Individualized Numeric Rating Scale [INRS] and Revised Face, Legs, Activity, Cry, Consolability [r-FLACC]) to more complex such as the Paediatric Pain Profile (PPP). Other reviews have provided details on the reliability and validity of the instruments [16-18]. Inter-rater reliability of most of the instruments is adequate, and construct validity-estimated by correlating the outcomes of a new scale with those of an existing scale-is sufficient [11,19-21]. The lack of a gold standard makes it impossible to determine real criterion validity. The instruments have been primarily studied in a hospital setting after surgery, with the exception of the Non-Communicating Children's Pain Checklist (NCCPC) and PPP [19, 21, 22].

These instruments generally have been validated for children from the age of 3 years and older, which is a major reason why neonates and infants with developmental 
disabilities are an understudied group. We know that a number of these children develop cerebral palsy later in life, but currently we do not know how to assess their pain. A study by Stevens et al. found that infants at risk for neurological impairment showed a less intensive behavioral response to heel lance than did infants with a low risk for neurological impairment [23]. Our own group found that the COMFORT behavior scale is also valid for the detection of pain in neonates and infants with Down syndrome [24].

The available instruments primarily focus on behavioral indicators of pain. Physicians, however, tend to prefer physiological parameters for pain and distress assessment [25]. Acute pain increases the heart rate and blood pressure through the connections from the spinoreticular tract to the brainstem and then further on to the sympathetic and parasympathic efferent pathways. Nevertheless, heart rate and blood pressure monitoring is not sensitive and specific enough for the measurement of pain in the intensive-care setting [26]. In some situations, however, for example during general anesthesia, heart rate and blood pressure monitoring is the only available measure of pain. This is why bedside devices based on 'objective surrogate' measures have been developed, such as the Bispectral index [27] to assess the level of consciousness, and skin conductance [28] to assess distress and pain.

Unfortunately, Bispectral index monitoring of intellectually disabled children is not reliable enough in clinical practice since the values could be lower than in intellectually unaffected children. This could lead to misinterpretation of the state of consciousness [29]. The method of measuring skin conductance is based on stress-induced sweating of the palm of the hand and/or the soles of the feet [30]. Sweat glands are stimulated by sympathetic excitatory efferent neurons and sweat is released within 1-2 s of excitation, increasing the skin conductance because skin resistance is then reduced. However, the technique for measuring skin conductance needs to be improved and standardized since studies give mixed results about the sensitivity and specificity of this method for the measurement of pain $[31,32]$.

A more recent study evaluated two other physiological parameters for the detection of pain in children: heart rate variability and pupillary reflex dilatation [33]. These two parameters were measured during surgery in 58 children between 2 and 16 years old. A rapid change in heart rate variability and pupillary reflex dilatation was noted to occur after skin incision when regional anesthesia failed [33].

Another area of pain assessment is the analysis of salivary cortisol levels and other biomarkers [34]. New, simple techniques have been developed to determine cortisol levels with the use of a smartphone app [35].
Treister et al. found that combining hemodynamic parameters such as heart rate variability and skin conductance discriminated better between pain and no pain than the single parameter approach [36]. Multimodal assessment of pain in intellectually disabled children is certainly worthy of study, because these are the patients who could especially benefit from more advanced pain assessment methods then having to rely on interpretation of their behavior by caregivers.

\section{Implementation and Knowledge Transfer}

Six pain assessment instruments for children with intellectual disabilities $>3$ years of age are available (Table 2). The question is how often these are really used in daily practice in hospitals and other facilities, bearing in mind that pain management for children without intellectual disabilities in pediatric settings still can be improved [37, 38]. One of the reasons is the existence of barriers to regular pain assessment in hospitalized children; this has been shown for the assessment of postoperative pain [3941]. Improving adherence to pain assessment can be achieved by the availability of pain resource nurses [42] and one-on-one coaching [43]. A large Canadian multicenter study showed that pain management improved in those settings where an Evidence-based Practice for Improving Quality (EPIQ) approach toward pain management was applied [44]. This involved efforts from external pain experts and local facilitators. Seeing the great effort needed to improve pain management for children without intellectual disabilities, it is obvious that this is even more difficult for children with intellectual disabilities. Pediatric patients with intellectual disabilities will always form a minority group and adherence to pain assessment with these specific tools is hampered because they are not used routinely. To the best of our knowledge, only one study has described the implementation process of pain assessment for children with intellectual disabilities, in a post-surgical/trauma unit and a rehabilitation unit [45]. Over a 4-month period, 30 children were eligible for inclusion. The majority of nurses (93\% of 133 nurses) preferred the r-FLACC over the PPP compared with $46 \%$ of the 20 parents who participated. Six months after implementation, use of the r-FLACC was evaluated; 37 of the 66 audited patients $(56.7 \%)$ had indeed been assessed with the r-FLACC. The authors concluded that to sustain a practice change one needs to monitor the process and continue with measures such as one-on-one training [45].

Although adequate pain assessment is the cornerstone of pain management, the next step is prescribing adequate analgesic agents with appropriate dosing instructions. In two retrospective studies, intellectually disabled children in 
general received lower doses of intraoperative opioids compared with controls [46, 47]. This practice might be due to physicians' perceptions about the patient's sensitivity to pain or response to analgesia. Malviya et al. reported that $89 \%$ of the physicians they surveyed tended to prescribe sub-therapeutic doses of analgesics to children with an intellectual disability [48]. The authors considered lack of education and knowledge as the primary barriers to effective pain management in intellectually disabled children [48]. In a survey among Dutch anesthesiologists on their pain management in intellectually disabled children [49] around $90 \%$ of the respondents indicated they give similar doses of intraoperative opioids to intellectually and non-intellectually disabled children, which is in stark contrast to the findings of Malviya et al. [48] a few years earlier. However, only $3 \%$ of the anesthesiologists in the Dutch survey used a pain assessment instrument validated for intellectually disabled children.

Changing erroneous perceptions of caregivers with regard to pain sensitivity and response to sedation of intellectually disabled children is important since these perceptions could influence analgesia and sedation practices [50]. This would require training programs for pain specialists, collaboration with physicians specialized in the care for intellectually disabled individuals, and parent support groups. The relevant organizations such as IASP and the American Society of Anesthesiologists (ASA) should advocate for the development and implementation of treatment guidelines and support knowledge transition. At an institutional level, e-learning modules can be developed to train healthcare professionals in pain assessment and management, and stimulate them to adhere to the local guidelines.

\section{Pain Resulting From Co-Morbidities and Common Surgical Procedures}

The following sections will illustrate the value of the pain assessment instruments that have been developed for intellectually disabled children, as they are at risk for pain associated with co-morbidities and surgical procedures. Early recognition and treatment can be key to preventing the development of chronic pain. We know that around $15.4 \%$ of intellectually disabled adults suffers from chronic pain [51], the prevalence of chronic pain in children with intellectual disabilities is unknown.

Two conditions are particularly relevant to intellectually disabled children and will be discussed: gastro-esophageal reflux disease and self-injurious behavior. Then for the two bigger groups of intellectually disabled children, children with Down syndrome and cerebral palsy, the most common comorbidities and surgical procedures will be discussed.

Gastro-esophageal reflux disease is a major cause of pain in intellectually disabled children [52]. It may be associated with vomiting, pneumonia, and dental problems, all of which are potentially painful [53]. Validated questionnaires are available to quantify symptom frequency and severity of gastro-esophageal reflux [54]. Early detection and early treatment of gastro-esophageal reflux is key to preventing pain and other symptoms.

Thirteen percent of intellectually disabled individuals show self-injurious behavior such as head banging or selfbiting, and pain could be a setting event for this behavior (i.e., it is a way to express pain) [55]. The incidence of selfinjurious behavior in children with autism is reported to be up to $50 \%$, but only in a small percentage with pain as a setting event [56]. Algorithms for the assessment and treatment of the self-injurious behavior have been developed; however, it remains a very challenging condition for parents and healthcare professionals [56].

More than 80 different comorbidities have been associated with Down syndrome [57], and some—-such as a congenital heart defect—are present in more than $40 \%$ of children with Down syndrome [58]. Up to 20 years ago, Down syndrome was, at a number of institutions, a reason to withhold surgery for congenital duodenal obstruction or congenital heart defects [59]. This is no longer the case; surgery is offered nowadays and, in combination with improved therapy for pulmonary hypertension and leukemia, the 10-year survival of children with Down syndrome has improved to $91 \%$ [60]. With reduced mortality, the morbidity is higher in those who survive; therefore, adequate pain assessment and management is highly relevant in these children.

Cerebral palsy, on the other hand, is characterized by a very wide variation in the severity of motor, sensory, and neurological symptoms [61]. For example, intellectual disability is not always present in children with cerebral palsy, although they may show severe motor impairment. The prevalence of recurrent pain in children with cerebral palsy is $50-70 \%$ [10]. The associated spasticity or other musculoskeletal conditions such as scoliosis, muscle contractures, and hip dislocations are potential causes of pain [61]. These conditions require repetitive neurosurgical and orthopedic procedures. Joint contractures and deformities can cause entrapment of sensory and motor neurons and consequently neuropathic pain; a pain condition that requires a different approach. A small observational study showed that this type of neuropathic pain was present in 11 (38\%) of individuals with cerebral palsy [62].

\section{Altered Pharmacokinetics and Pharmacodynamics and Co-Medication}

It took quite some time before the determinants of developmental changes in infants and children on the pharmacokinetics of various drugs was recognized [63]. 
Table 3 Findings of pharmacokinetic and pharmacodynamic studies in individuals with Down syndrome

\begin{tabular}{llc}
\hline Drug & Pharmacokinetic findings & Pharmacodynamic findings \\
\hline $\begin{array}{l}\text { Analgesics } \\
\text { Paracetamol [91] }\end{array}$ & $\begin{array}{c}\text { Metabolism increased to glutathione- } \\
\text { derived conjugates and decreased to the } \\
\text { sulfate-derived conjugates }\end{array}$ & Not investigated \\
Morphine [71] & $\begin{array}{l}\text { No differences in clearance or volume of } \\
\text { distribution }\end{array}$ & $\begin{array}{c}\text { More oversedation in children with } \\
\text { Down syndrome }\end{array}$ \\
Other drugs & Not investigated & More bradycardia and hypotension \\
Sevoflurane [92,93] & Clearance 5\% lower in children with & More toxicity \\
Methotrexate [94] & Down syndrome & Clearance prolonged
\end{tabular}

Nowadays, age- and weight-specific dosing recommendations are formulated for an increasing number of drugs [63]. With regard to developmental pharmacokinetics of analgesics, huge steps have been taken towards evidencebased dosing of, for example, morphine in infants and children [64].

The increasing interest in pharmacokinetics of analgesics in intellectually disabled children is probably a result of studies reporting differences in pharmacodynamics between children with and without intellectual disabilities. In two retrospective studies, intellectually disabled children in general received lower doses of intraoperative opioids compared with controls [46, 47]. Children with Down syndrome have been described as more agitated and "difficult to sedate" after surgery [65]. One retrospective chart review study showed that children with Down syndrome more often received sedatives and muscle relaxants after cardiac surgery than children without Down syndrome [66]. However, two other retrospective chart review studies did not show any differences in analgesic requirements between the children with and without Down syndrome [67, 68].

Since there are only a handful of pharmacological studies on analgesics in intellectually disabled children, other studies on the pharmacokinetics of other drugs in intellectually disabled children will also be discussed here. Interestingly, almost all those studies were performed in individuals with Down syndrome, see Table 3. In general, intellectually disabled children are more at risk of developing drug-related side effects [69, 70] and the related signs may be more difficult to identify because history taking might be more challenging. Special attention is needed for drug-drug interactions with antiepileptic drugs, since these drugs are often prescribed to intellectually disabled children.

Looking at the pharmacokinetics of analgesics, the distribution and metabolism of paracetamol and morphine have been studied in individuals with Down syndrome (Table 3). Our own group performed a prospective trial on the pharmacokinetics of intravenous morphine after cardiac surgery in children with and without Down syndrome [71]. Population pharmacokinetic analysis revealed no statistically significant differences in the clearance or volume of distribution of morphine in children with and without Down syndrome. We concluded that there was no evidence to adjust morphine dosing after cardiac surgery in children with Down syndrome [71]. This brings us back to the rationale for performing these pharmacokinetic studies, which is the presumed difference in pharmacodynamics between children with and without intellectual disabilities.

Epilepsy is a very common comorbidity in intellectually disabled children. For example, up to $90 \%$ of children with Rett syndrome or Angelman syndrome suffer from epilepsy [72], compared with $8 \%$ of children with Down syndrome [73]. Many intellectually disabled children will therefore need lifelong treatment with antiepileptic drugs. Older antiepileptic drugs (i.e., phenytoin, phenobarbital, carbamazepine) may be expected to cause drug-drug interactions, since they are potent inducers of multiple cytochrome P450 enzymes [74]. The protein binding effects and enzyme induction of these drugs on the pharmacokinetics of sedative and analgesic drugs have been described by Kofke [75]. Plasma concentrations of analgesics and general anesthetics can either be increased or decreased based on the type of antiepileptic drug. An observational study found that adults who used antiepileptic drugs needed higher doses of fentanyl for the maintenance of general anesthesia than adults who did not use antiepileptic drugs [76], a possible effect of hepatic enzyme induction by the antiepileptic drugs. Newer antiepileptic drugs such as gabapentin, lamotrigine, and levetiracitam do not induce hepatic enzymes [6]. However, for example in children with Rett syndrome, older antiepileptic drugs such as sodium valproate, 
carbamazepine, and phenobarbital are still first-line agents and clinicians should therefore be aware of the enzyme inducing and inhibiting properties of these drugs [77]. Since these drugs are broad-spectrum inducers, pharmacokinetic studies on analgesics (such as fentanyl or morphine) can be justified in children requiring long-term treatment with these antiepileptic drugs.

\section{Use of Novel Strategies in Pharmacological Research}

How can pharmacological studies improve pain management in intellectually disabled children? Knowledge of pharmacokinetics of drugs is required for the development of model-based dosing regimens. We have shown that more knowledge on drug-drug interactions is required, that children with intellectual disabilities are more at risk for side effects, and that the pharmacodynamics can be altered in various groups of intellectually disabled children.

New sampling methods have improved the feasibility of pediatric pharmacokinetic studies, as smaller blood volumes and fewer samples are required for analysis [78]. Furthermore, opportunistic sampling (i.e., when a sample is taken for clinical purposes, a little of the volume is used for analysis of the level of drugs) has now been accepted by the regulatory bodies [79].

Data from population pharmacokinetic and pharmacodynamic studies can be used for simulations. These simulations then can form the basis for the design of 'proof-ofprinciple' studies, preferably randomized controlled trials [80]. This approach has successfully been applied in neonates, infants, and children without intellectual disability (e.g., for midazolam, morphine and paracetamol) [81-83].

A perfect example is the dosing recommendation for the use of propofol in children during correction of idiopathic scoliosis [84]. The pharmacokinetic results were added to a larger dataset and using population pharmacokinetic methods, the clearance of propofol could be predicted and subsequently a dosing recommendation could be made. A reasonably small sample size is required for those studies and therefore it is feasible to perform those studies in small groups of intellectually disabled children [78].

Given the wide variety of causes of intellectual disability, comorbidities, and co-medication in these children, it is not easy to set up large-scale pharmacological trials. 'Model' drugs can be used for classes of drugs metabolized by the same enzymes of the cytochrome P450 system and other metabolic pathways. This system approach renders great opportunities for future pharmacological studies. Systematic and careful monitoring of multimodal pharmacodynamic outcome parameters could be a starting point [85], preferably with a more advanced bedside device that combines, for example, heart rate variability with skin conductance measurements. Analysis of the pharmacokinetics is justified when a large difference in effect or safety in children with and without intellectual disabilities can be expected. These pharmacokinetic analyses would also be useful when pharmacokinetic variability is presumed to be related to the intellectual disability.

\section{Conclusion}

Intellectually disabled children are often excluded from pain research because of their inability to self-report pain, the variability in intellectually disability, ethical considerations with regard to informed consent, unknown and potential altered pharmacokinetics of analgesics, and use of co-medication. Seeing that they are at high risk for acute and chronic pain and often require more surgical interventions, there is every reason to optimize the pain management for intellectually disabled children. The ultimate goal is to predict the amount of acute and chronic pain after surgery, and thus the analgesia or sedation requirements, leading to safe and effective pain management.

We therefore make a plea for prescribers, researchers, patient organizations, pharmaceutical companies, and policy makers to study evidence-based and effective pharmacotherapy in these children in properly designed trials. In the meantime, parents and clinicians must resort to validated pain assessment instruments, and preferably the r-FLACC score. Hospitals and other healthcare institutions are recommended to invest in implementation of the pain assessment tools in clinical practice and in education of caregivers and parents.

Acknowledgments Ko Hagoort is thanked for editing the text.

Conflict of interest disclosure AJV, TGdL, MvD, and DT declare that they have no conflict of interest.

Funding No funding was received for this work.

Open Access This article is distributed under the terms of the Creative Commons Attribution-NonCommercial 4.0 International License (http://creativecommons.org/licenses/by-nc/4.0/), which permits any noncommercial use, distribution, and reproduction in any medium, provided you give appropriate credit to the original author(s) and the source, provide a link to the Creative Commons license, and indicate if changes were made.

\section{References}

1. Schalock R. Intellectual disability: definition, classification, and systems of supports. Washington DC: American Association on Intellectual and Developmental Disabilities; 2010.

2. van Bakel M, Einarsson I, Arnaud C, Craig S, Michelsen SI, Pildava S, et al. Monitoring the prevalence of severe intellectual 
disability in children across Europe: feasibility of a common database. Dev Med Child Neurol. 2014;56(4):361-9.

3. van Gameren-Oosterom HB, Buitendijk SE, Bilardo CM, van der Pal-de Bruin KM, Van Wouwe JP, Mohangoo AD. Unchanged prevalence of Down syndrome in the Netherlands: results from an 11-year nationwide birth cohort. Prenat Diagn. 2012;32(11):1035-40.

4. Willemsen MH, Kleefstra T. Making headway with genetic diagnostics of intellectual disabilities. Clin Genet. 2014;85(2):101-10.

5. de Knegt N, Scherder E. Pain in adults with intellectual disabilities. Pain. 2011;152(5):971-4.

6. Perks A, Cheema S, Mohanraj R. Anaesthesia and epilepsy. Br J Anaesth. 2012;108(4):562-71.

7. Down JL. On some of the mental affections of childhood and youth: Being the Lettsomian lectures delivered before the Medical society of London in 1887, together with other papers. London: J. \& A. Churchill; 1887.

8. Bos W, Tromp K, Tibboel D, Pinxten W. Ethical aspects of clinical research with minors. Eur J Pediatr. 2013;172(7):859-66.

9. Kleiber N, Tromp K, Mooij MG, van de Vathorst S, Tibboel D, de Wildt SN.Ethics of drug research in the pediatric intensive care unit. Paediatr Drugs. 2015;17(1):43-53.

10. Belew J, Barney C, Schwantes S, Tibboel D, Valkenburg A, Symons F. Pain in Children with intellectual or developmental disabilities. In: Zempsky W, Stevens B, McGrath P, Walker S, editors. Oxford textbook of paediatric pain. Oxford: Oxford University Press; 2013.

11. Solodiuk JC, Scott-Sutherland J, Meyers M, Myette B, Shusterman C, Karian VE, et al. Validation of the Individualized Numeric Rating Scale (INRS): a pain assessment tool for nonverbal children with intellectual disability. Pain. 2010;150(2):231-6.

12. Pain terms: a list with definitions and notes on usage. Recommended by the IASP Subcommittee on Taxonomy. Pain. 1979;6(3):249.

13. Anand KJ, Craig KD. New perspectives on the definition of pain. Pain. 1996;67(1):3-6.

14. Loggia ML, Napadow V. Multi-parameter autonomic-based pain assessment: more is more? Pain. 2012;153(9):1779-80.

15. von Baeyer CL, Spagrud LJ. Systematic review of observational (behavioral) measures of pain for children and adolescents aged 3 to 18 years. Pain. 2007;127(1-2):140-50.

16. Crosta QR, Ward TM, Walker AJ, Peters LM. A review of pain measures for hospitalized children with cognitive impairment. J Spec Pediatr Nurs. 2014;19(2):109-18.

17. Valkenburg AJ, van Dijk M, de Klein A, van den Anker JN, Tibboel D. Pain management in intellectually disabled children: assessment, treatment, and translational research. Dev Disabil Res Rev. 2010;16(3):248-57.

18. Ely E, Chen-Lim ML, Zarnowsky C, Green R, Shaffer S, Holtzer B. Finding the evidence to change practice for assessing pain in children who are cognitively impaired. J Pediatr Nurs. 2012;27(4):402-10.

19. Breau LM, Finley GA, McGrath PJ, Camfield CS. Validation of the non-communicating children's pain checklist-postoperative version. Anesthesiology. 2002;96(3):528-35.

20. Malviya S, Voepel-Lewis T, Burke C, Merkel S, Tait AR. The revised FLACC observational pain tool: improved reliability and validity for pain assessment in children with cognitive impairment. Paediatr Anaesth. 2006;16(3):258-65.

21. Hunt A, Wisbeach A, Seers K, Goldman A, Crichton N, Perry L, et al. Development of the paediatric pain profile: role of video analysis and saliva cortisol in validating a tool to assess pain in children with severe neurological disability. J Pain Symptom Manag. 2007;33(3):276-89.
22. Hunt A, Goldman A, Seers K, Crichton N, Mastroyannopoulou $\mathrm{K}$, Moffat V, et al. Clinical validation of the paediatric pain profile. Dev Med Child Neurol. 2004;46(1):9-18.

23. Stevens B, McGrath P, Gibbins S, Beyene J, Breau L, Camfield $\mathrm{C}$, et al. Determining behavioural and physiological responses to pain in infants at risk for neurological impairment. Pain. 2007;127(1-2):94-102.

24. Valkenburg AJ, Boerlage AA, Ista E, Duivenvoorden HJ, Tibboel D, van Dijk M. The COMFORT-Behavior scale is useful to assess pain and distress in 0-to 3-year-old children with Down syndrome. Pain. 2011;152(9):2059-64.

25. Berde $C$, McGrath P. Pain measurement and Beecher's challenge: 50 years later. Anesthesiology. 2009;111(3):473-4.

26. van Dijk M, de Boer JB, Koot HM, Tibboel D, Passchier J, Duivenvoorden HJ. The reliability and validity of the COMFORT scale as a postoperative pain instrument in 0 to 3 -year-old infants. Pain. 2000;84(2-3):367-77.

27. Davidson AJ. Monitoring the anaesthetic depth in children-an update. Curr Opin Anaesthesiol. 2007;20(3):236-43.

28. Davidson AJ. Measuring anesthesia in children using the EEG. Paediatr Anaesth. 2006;16(4):374-87.

29. Valkenburg AJ, de Leeuw TG, Tibboel D, Weber F. Lower bispectral index values in children who are intellectually disabled. Anesth Analg. 2009;109(5):1428-33.

30. Storm H. Development of emotional sweating in preterms measured by skin conductance changes. Early Hum Dev. 2001;62(2):149-58.

31. Valkenburg AJ, Niehof SP, van Dijk M, Verhaar EJ, Tibboel D. Skin conductance peaks could result from changes in vital parameters unrelated to pain. Pediatr Res. 2012;71(4 Pt 1):375-9.

32. Choo EK, Magruder W, Montgomery CJ, Lim J, Brant R, Ansermino JM. Skin conductance fluctuations correlate poorly with postoperative self-report pain measures in school-aged children. Anesthesiology. 2010;113(1):175-82.

33. Migeon A, Desgranges FP, Chassard D, Blaise BJ, De Queiroz M, Stewart A, et al. Pupillary reflex dilatation and analgesia nociception index monitoring to assess the effectiveness of regional anesthesia in children anesthetised with sevoflurane. Paediatr Anaesth. 2013;23(12):1160-5.

34. Symons FJ, ElGhazi I, Reilly BG, Barney CC, Hanson L, Panoskaltsis-Mortari A, et al. Can biomarkers differentiate pain and no pain subgroups of nonverbal children with cerebral palsy? A preliminary investigation based on noninvasive saliva sampling. Pain Med. 2015;16(2):249-56.

35. Zangheri M, Cevenini L, Anfossi L, Baggiani C, Simoni P, Di Nardo F, et al. A simple and compact smartphone accessory for quantitative chemiluminescence-based lateral flow immunoassay for salivary cortisol detection. Biosens Bioelectron. 2015;15(64):63-8.

36. Treister R, Kliger M, Zuckerman G, Aryeh IG, Eisenberg E. Differentiating between heat pain intensities: the combined effect of multiple autonomic parameters. Pain. 2012;153(9):1807-14.

37. Franck LS, Bruce E. Putting pain assessment into practice: why is it so painful? Pain Res Manag. 2009;14(1):13-20.

38. MacLaren J, Kain ZN. Research to practice in pediatric pain: what are we missing? Pediatrics. 2008;122(2):443-4.

39. Czarnecki ML, Simon K, Thompson JJ, Armus CL, Hanson TC, Berg KA, et al. Barriers to pediatric pain management: a nursing perspective. Pain Manag Nurs. 2011;12(3):154-62.

40. Czarnecki ML, Salamon KS, Thompson JJ, Hainsworth KR. Do barriers to pediatric pain management as perceived by nurses change over time? Pain Manag Nurs. 2014;15(1):292-305.

41. Twycross A. Nurses' views about the barriers and facilitators to effective management of pediatric pain. Pain Manag Nurs. 2013;14(4):e164-72.

42. Ellis JA, McCleary L, Blouin R, Dube K, Rowley B, MacNeil M, et al. Implementing best practice pain management in a pediatric hospital. J Spec Pediatr Nurs. 2007;12(4):264-77. 
43. Johnston CC, Gagnon A, Rennick J, Rosmus C, Patenaude H, Ellis $\mathrm{J}$, et al. One-on-one coaching to improve pain assessment and management practices of pediatric nurses. J Pediatr Nurs. 2007;22(6):467-78.

44. Stevens BJ, Yamada J, Estabrooks CA, Stinson J, Campbell F, Scott SD, et al. Pain in hospitalized children: effect of a multidimensional knowledge translation strategy on pain process and clinical outcomes. Pain. 2014;155(1):60-8.

45. Chen-Lim ML, Zarnowsky C, Green R, Shaffer S, Holtzer B, Ely E. Optimizing the assessment of pain in children who are cognitively impaired through the quality improvement process. J Pediatr Nurs. 2012;27(6):750-9.

46. Koh JL, Fanurik D, Harrison RD, Schmitz ML, Norvell D. Analgesia following surgery in children with and without cognitive impairment. Pain. 2004;111(3):239-44.

47. Long LS, Ved S, Koh JL. Intraoperative opioid dosing in children with and without cerebral palsy. Paediatr Anaesth. 2009;19(5):513-20.

48. Malviya S, Voepel-Lewis T, Merkel S, Tait A. Difficult pain assessment and lack of clinician knowledge are ongoing barriers to effective pain management in children with cognitive impairment. Acute Pain. 2005;1(7):27-32.

49. Valkenburg AJ, van der Kreeft SM, de Leeuw TG, Stolker RJ, Tibboel D, van Dijk M. Pain management in intellectually disabled children: a survey of perceptions and current practices among Dutch anesthesiologists. Pediatr Anesth. 2012; 22(7):682-9.

50. Walker SM. Perioperative care of neonates with Down's syndrome: should it be different? Br J Anaesth. 2012;108(2):177-9.

51. Walsh M, Morrison TG, McGuire BE. Chronic pain in adults with an intellectual disability: prevalence, impact, and health service use based on caregiver report. Pain. 2011;15:1-7.

52. Gossler A, Schalamon J, Huber-Zeyringer A, Hollwarth ME. Gastroesophageal reflux and behavior in neurologically impaired children. J Pediatr Surg. 2007;42(9):1486-90.

53. de Veer AJ, Bos JT, Niezen-de Boer RC, Bohmer CJ, Francke AL. Symptoms of gastroesophageal reflux disease in severely mentally retarded people: a systematic review. BMC Gastroenterol. 2008;8:23.

54. Deal L, Gold BD, Gremse DA, Winter HS, Peters SB, Fraga PD, et al. Age-specific questionnaires distinguish GERD symptom frequency and severity in infants and young children: development and initial validation. J Pediatr Gastroenterol Nutr. 2005;41(2):178-85.

55. Courtemanche A, Schroeder S, Sheldon J, Sherman J, Fowler A. Observing signs of pain in relation to self-injurious behaviour among individuals with intellectual and developmental disabilities. J Intellect Disabil Res. 2012;56(5):501-15.

56. Minshawi NF, Hurwitz S, Morriss D, McDougle CJ. Multidisciplinary assessment and treatment of self-injurious behavior in autism spectrum disorder and intellectual disability: integration of psychological and biological theory and approach. J Autism Dev Disord. 2015;45(6):1541-68.

57. Patterson D. Molecular genetic analysis of Down syndrome. Hum Genet. 2009;126(1):195-214.

58. Fudge JC Jr, Li S, Jaggers J, O’Brien SM, Peterson ED, Jacobs JP, et al. Congenital heart surgery outcomes in Down syndrome: analysis of a national clinical database. Pediatrics. 2010;126(2):315-22.

59. Leonard S, Bower C, Petterson B, Leonard H. Survival of infants born with Down's syndrome: 1980-96. Paediatr Perinat Epidemiol. 2000;14(2):163-71.

60. Rankin J, Tennant PW, Bythell M, Pearce MS. Predictors of survival in children born with Down syndrome: a registry-based study. Pediatrics. 2012;129(6):e1373-81.

61. Colver A, Fairhurst C, Pharoah PO. Cerebral palsy. Lancet. 2014;383(9924):1240-9.
62. Frascarelli M, Frascarelli F, Gentile MG, Serrao M, De Santis F, Pierelli F, et al. Entrapment neuropathy in patients with spastic cerebral palsy. Acta neurologica Scandinavica. 2005;112(3): 178-82.

63. Kearns GL, Abdel-Rahman SM, Alander SW, Blowey DL, Leeder JS, Kauffman RE. Developmental pharmacology-drug disposition, action, and therapy in infants and children. N Engl J Med. 2003;349(12):1157-67.

64. Krekels EH, Tibboel D, de Wildt SN, Ceelie I, Dahan A, van Dijk $\mathrm{M}$, et al. Evidence-based morphine dosing for postoperative neonates and infants. Clin Pharmacokinet. 2014;53(6):553-63.

65. Mitchell V, Howard R, Facer E. Down's syndrome and anaesthesia. Paediatr Anaesth. 1995;5(6):379-84.

66. Gakhal B, Scott CS, MacNab AJ. Comparison of morphine requirements for sedation in Down's syndrome and non-Down's patients following paediatric cardiac surgery. Paediatr Anaesth. 1998;8(3):229-33.

67. Valkenburg AJ, van Dijk M, de Leeuw TG, Meeussen CJ, Knibbe CA, Tibboel D. Anaesthesia and postoperative analgesia in surgical neonates with or without Down's syndrome: is it really different? Br J Anaesth. 2012;108(2):295-301.

68. Van Driest SL, Shah A, Marshall MD, Xu H, Smith AH, McGregor TL, et al. Opioid use after cardiac surgery in children with Down syndrome. Pediatr Crit Care Med. 2013;14(9):862-8.

69. Reiss S, Aman MG. The international consensus process on psychopharmacology and intellectual disability. J Intellect Disabil Res. 1997;41:448-55.

70. Arnold LE. Clinical pharmacological issues in treating psychiatric disorders of patients with mental retardation. Ann Clin Psychiatry Off J Am Acad Clin Psychiatr. 1993;5(3):189-97.

71. Valkenburg AJ. Without uttering a word: pain assessment and management in intellectually disabled children: Erasmus University, Rotterdam, The Netherlands; 2012. http://hdl.handle. net/1765/37994.

72. Leung HT, Ring H. Epilepsy in four genetically determined syndromes of intellectual disability. J Intellect Disabil Res. 2013;57(1):3-20.

73. Goldberg-Stern H, Strawsburg RH, Patterson B, Hickey F, Bare M, Gadoth N, et al. Seizure frequency and characteristics in children with Down syndrome. Brain Dev. 2001;23(6):375-8.

74. Uman LS, Birnie KA, Noel M, Parker JA, Chambers CT, McGrath PJ, et al. Psychological interventions for needle-related procedural pain and distress in children and adolescents. Cochrane Database Syst Rev. 2013;10:CD005179.

75. Kofke WA. Anesthetic management of the patient with epilepsy or prior seizures. Curr Opin Anaesthesiol. 2010;23(3):391-9.

76. Tempelhoff R, Modica PA, Spitznagel EL. Anticonvulsant therapy increases fentanyl requirements during anaesthesia for craniotomy. Can J Anaesth. 1990;37(3):327-32.

77. Zabalia M. Beyond misconceptions: assessing pain in children with mild to moderate intellectual disability. Front Public Health. 2013;1:23.

78. De Cock RF, Piana C, Krekels EH, Danhof M, Allegaert K, Knibbe CA. The role of population PK-PD modelling in paediatric clinical research. Eur J Clin Pharmacol. 2011;67(Suppl 1):5-16.

79. Laughon MM, Benjamin DK Jr, Capparelli EV, Kearns GL, Berezny K, Paul IM, et al. Innovative clinical trial design for pediatric therapeutics. Expert Rev Clin Pharmacol. 2011;4(5):643-52.

80. Krekels EH, DeJongh J, van Lingen RA, van der Marel CD, Choonara I, Lynn AM, et al. Predictive performance of a recently developed population pharmacokinetic model for morphine and its metabolites in new datasets of (preterm) neonates, infants and children. Clin Pharmacokinet. 2011;50(1):51-63.

81. Knibbe CA, Krekels EH, van den Anker JN, DeJongh J, Santen $\mathrm{GW}$, van Dijk M, et al. Morphine glucuronidation in preterm 
neonates, infants and children younger than 3 years. Clin Pharmacokinet. 2009;48(6):371-85.

82. Peeters MYM, Prins SA, Knibbe CAJ, DeJongh J, Mathot RAA, Warris $\mathrm{C}$, et al. Pharmacokinetics and pharmacodynamics of midazolam and metabolites in nonventilated infants after craniofacial surgery. Anesthesiology. 2006;105(6):1135-46.

83. van der Marel CD, van Lingen RA, Pluim MA, Scoones G, van Dijk M, Vaandrager JM, et al. Analgesic efficacy of rectal versus oral acetaminophen in children after major craniofacial surgery. Clin Pharmacol Ther. 2001;70(1):82-90.

84. Diepstraten J, Chidambaran V, Sadhasivam S, Blusse van OudAlblas HJ, Inge T, van Ramshorst B, et al. An integrated population pharmacokinetic meta-analysis of propofol in morbidly obese and nonobese adults, adolescents, and children. CPT Pharmacomet Syst Pharmacol. 2013;2:e73.

85. Anderson BJ. My child is unique; the pharmacokinetics are universal. Paediatr Anaesth. 2012;22(6):530-8.

86. Terstegen C, Koot HM, de Boer JB, Tibboel D. Measuring pain in children with cognitive impairment: pain response to surgical procedures. Pain. 2003;103(1-2):187-98.

87. Duivenvoorden HJ, Tibboel D, Koot HM, van Dijk M, Peters JW. Pain assessment in profound cognitive impaired children using the Checklist Pain Behavior; is item reduction valid? Pain. 2006;126(1-3):147-54.

88. Breau LM, Camfield C, McGrath PJ, Rosmus C, Finley GA. Measuring pain accurately in children with cognitive impairments: refinement of a caregiver scale. J Pediatr. 2001;138(5):721-7.
89. Breau LM, McGrath PJ, Camfield C, Rosmus C, Finley GA. Preliminary validation of an observational pain checklist for persons with cognitive impairments and inability to communicate verbally. Dev Med Child Neurol. 2000;42(9):609-16.

90. Voepel-Lewis T, Merkel S, Tait AR, Trzcinka A, Malviya S. The reliability and validity of the Face, Legs, Activity, Cry, Consolability observational tool as a measure of pain in children with cognitive impairment. Anesth Analg. 2002;95(5):1224-9.

91. Griener JC, Msall ME, Cooke RE, Corcoran GB. Noninvasive determination of acetaminophen disposition in Down's syndrome. Clin Pharmacol Ther. 1990;48(5):520-8.

92. Kraemer FW, Stricker PA, Gurnaney HG, McClung H, Meador MR, Sussman E, et al. Bradycardia during induction of anesthesia with sevoflurane in children with Down syndrome. Anesth Analg. 2010;111(5):1259-63.

93. Bai W, Voepel-Lewis T, Malviya S. Hemodynamic changes in children with Down syndrome during and following inhalation induction of anesthesia with sevoflurane. J Clin Anesth. 2010;22(8):592-7.

94. Buitenkamp TD, Mathôt RAA, de Haas V, Pieters R, Zwaan CM. Methotrexate-induced side effects are not due to differences in pharmacokinetics in children with Down syndrome and acute lymphoblastic leukemia. Haematologica. 2010;95(7):1106-13.

95. Stowe CD, Phelps SJ. Altered clearance of theophylline in children with Down syndrome: a case series. J Clin Pharmacol. 1999;39(4):359-65. 